\title{
Study on Connection Interval Design of Carbon Fiber B - pillar Reinforcement
}

\author{
Qingmian Wan, Lei Wu
}

Advanced Technology Department, Shanghai Automotive Industry Corporation Limited, Shanghai, China

E-mail: wqqm00@163.com

Keywords: carbon fiber; B-pillar; riveting

\begin{abstract}
B-pillar reinforcement is an important safety part for the side of the vehicle. In order to cope with more stringent regulatory standards, B-pillar reinforcement material has been developed from cold stamping steel plate into hot-formed steel plate. At the same time, carbon fiber B-pillar reinforcement is also an important direction of development. In this paper, a simulation of the rivet connection of carbon fiber B-pillar reinforcement is carried out, which is under the requirement of side collision and the effect of different connection strength on vehicle performance of carbon fiber B-pillar. Finally, the effective distribution of riveting is obtained at the specified request.
\end{abstract}

\section{Introduction}

Due to the current requirement of the body lightweight, the latest BMW 7 series cars have begun to use carbon fiber materials to produce B-pillar reinforcement. Carbon fiber B-pillar reinforcement has the advantages of light weight, high modulus, and strong impact resistance and so on. Under the background of the vehicle lightweight, the development of fiber composite B-pillar reinforcement has become a new direction of research. And the connection design of the carbon fiber B-pillar reinforcement is still the key to its application. In this paper, the influence of different connection strength of B-pillar on vehicle performance will be discussed.

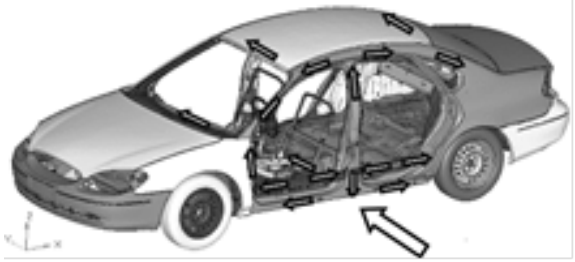

Fig.1. The path of the side collision kinetic energy

The reinforcement of B-pillar plays an important role in vehicle collision. It is also an important force component in vehicle side impact, as shown in Fig.1. B-pillar reinforcement is required to absorb the impact of the body collision. [1]

Because this experiment is only to analyze the influence factors of the reinforcement of the B-pillar, so if the vehicle analysis method is adopted, the experimental variables may be increased, and the accumulation of experimental error may be increased as well. [2] Therefore, in this experiment, the collision simplified model is used to study the B-pillar connection method. [3]

In order to simplify the simulation of the B-pillar reinforcement, the B-pillar reinforcement model is simplified according to the cross-section design. As shown in Fig. 2 and Fig. 3, the cross-section expansion model is used instead of the B-pillar reinforcement part to reduce the influence of the interference term. 


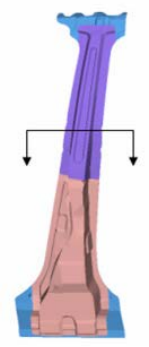

(a)

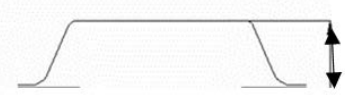

(b)

Fig.2 (a) B-pillar reinforcement front view (b) B-pillar reinforcement section

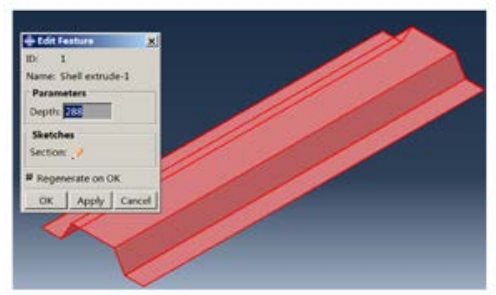

(a)

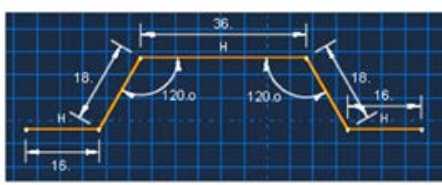

(b)

Fig.3(a) B-pillar simplified diagram (b) Cross section simplified diagram

The B-pillar reinforcement section is extended into a simplified model diagram, as shown in Figures 3(a) and 3(b), and the simulation is done according to the connection method of B-pillar reinforcement.

\section{Modeling and Simulation}

\subsection{The same type of top rivet connection}

Carbon fiber B-pillar reinforcement using the rivet method, the B-pillar reinforcing part is connected to the other body parts. The connecting simulation model in accordance with the rivet material property settings, and the connection parts in accordance with the real car parts to connect and model. First of all, using three-point simulation to simulate the damage of B-pillar reinforcement connections during side collision of vehicle. External material is set to steel, the internal material is set to carbon fiber material. According to the different arrangement of rivets, the connection is classified, including the connection scheme of rivets with different intervals.

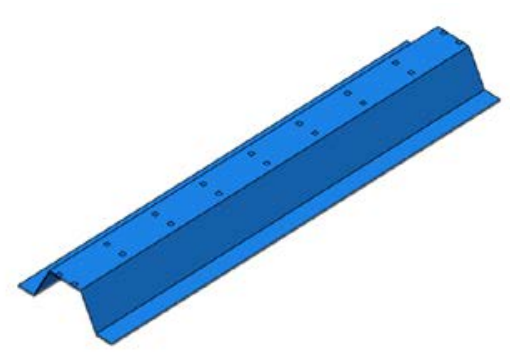

(a)

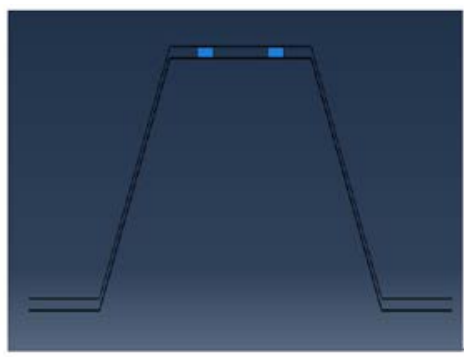

(b)

Fig.4

Distance between rivets are carried out from 4 times the rivet diameter ( $\mathrm{D}=6.17 \mathrm{~mm}$ ) interval $24.77 \mathrm{~mm}$ to 12 times the diameter of rivet spacing $(74.3 \mathrm{~mm})$, followed by the simulation of the effect of different intervals in order to verify the performance of the parts with different spacing riveting structure. 
Table 1 Simplified parameter list for rivet connection

\begin{tabular}{|c|c|c|c|c|c|}
\hline Name & $\begin{array}{c}\text { connecti } \\
\text { on model } \\
\text { width }\end{array}$ & $\begin{array}{c}\text { Bevel } \\
\text { angle } \\
\text { of } \\
\text { model }\end{array}$ & $\begin{array}{c}\text { Connec } \\
\text { tion } \\
\text { model } \\
\text { height }\end{array}$ & $\begin{array}{c}\text { Connec } \\
\text { tion } \\
\text { model } \\
\text { length }\end{array}$ & $\begin{array}{c}\text { rivet } \\
\text { space }\end{array}$ \\
\hline $\mathrm{a}$ & $86 \mathrm{~mm}$ & $60^{\circ}$ & 15.5 & $288 \mathrm{~mm}$ & $24.77 \mathrm{~mm}$ \\
\hline $\mathrm{b}$ & $86 \mathrm{~mm}$ & $60^{\circ}$ & 15.5 & $288 \mathrm{~mm}$ & $37.15 \mathrm{~mm}$ \\
\hline $\mathrm{c}$ & $86 \mathrm{~mm}$ & $60^{\circ}$ & 15.5 & $288 \mathrm{~mm}$ & $49.5 \mathrm{~mm}$ \\
\hline $\mathrm{d}$ & $86 \mathrm{~mm}$ & $60^{\circ}$ & 15.5 & $288 \mathrm{~mm}$ & $59.4 \mathrm{~mm}$ \\
\hline $\mathrm{e}$ & $86 \mathrm{~mm}$ & $60^{\circ}$ & 15.5 & $288 \mathrm{~mm}$ & $74.3 \mathrm{~mm}$ \\
\hline
\end{tabular}

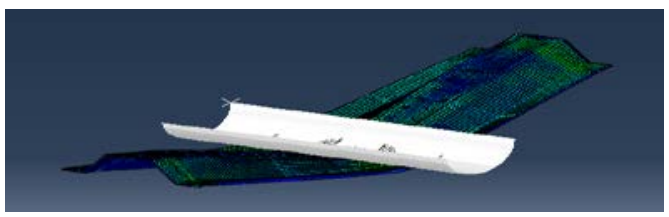

(a)

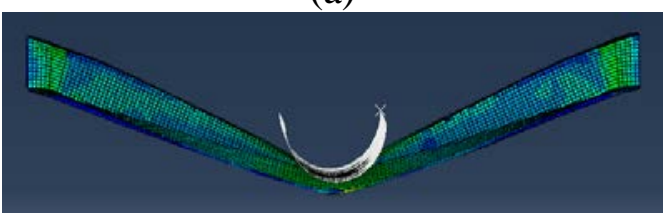

(b)

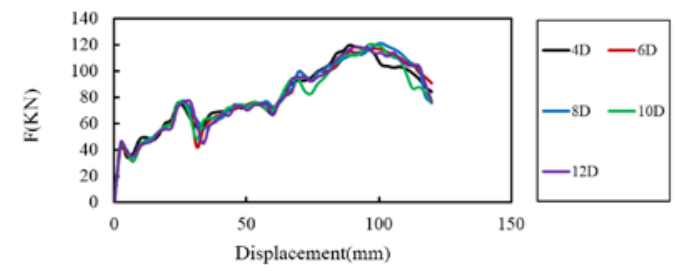

(c)

Fig.5 (a) Collapsing deformation diagram (b) Collapsing deformation diagram (c) Displacement diagram

Table 2 Simplified model simulation results

\begin{tabular}{|c|c|c|c|c|c|c|}
\hline Name & $\begin{array}{c}\text { connection } \\
\text { model } \\
\text { width }\end{array}$ & $\begin{array}{c}\text { Bevel } \\
\text { angle of } \\
\text { model }\end{array}$ & $\begin{array}{c}\text { Connection } \\
\text { model height }\end{array}$ & $\begin{array}{c}\text { Connectio } \\
\text { n model } \\
\text { length }\end{array}$ & rivet space & $\begin{array}{c}\text { Maximum } \\
\text { load }\end{array}$ \\
\hline $\mathrm{a}$ & $86 \mathrm{~mm}$ & $60^{\circ}$ & $15.5 \mathrm{~mm}$ & $288 \mathrm{~mm}$ & $24.77 \mathrm{~mm}$ & $121 \mathrm{KN}$ \\
\hline $\mathrm{b}$ & $86 \mathrm{~mm}$ & $60^{\circ}$ & $15.5 \mathrm{~mm}$ & $288 \mathrm{~mm}$ & $37.15 \mathrm{~mm}$ & $121 \mathrm{KN}$ \\
\hline $\mathrm{C}$ & $86 \mathrm{~mm}$ & $60^{\circ}$ & $15.5 \mathrm{~mm}$ & $288 \mathrm{~mm}$ & $49.5 \mathrm{~mm}$ & $121 \mathrm{KN}$ \\
\hline $\mathrm{d}$ & $86 \mathrm{~mm}$ & $60^{\circ}$ & $15.5 \mathrm{~mm}$ & $288 \mathrm{~mm}$ & $59.4 \mathrm{~mm}$ & $121 \mathrm{KN}$ \\
\hline $\mathrm{e}$ & $86 \mathrm{~mm}$ & $60^{\circ}$ & $15.5 \mathrm{~mm}$ & $288 \mathrm{~mm}$ & $74.3 \mathrm{~mm}$ & $121 \mathrm{KN}$ \\
\hline
\end{tabular}

From the final simulation simulation results, in the case of no slippage deformation of the parts, different rivets interval does not significantly affect the bearing capacity of parts, parts bearing capacity is still mainly depends on the material properties of the parts themselves. 


\subsection{The same type of flanging connection}

According to the rivet connection material property settings, and at the same time, the parts are connected according to the connection of the real vehicle components, modeling. First of all, three-point simulation, simulation vehicle side collision when the B-pillar reinforcement connection damage. External material is set to steel, the internal material is set to carbon fiber material. According to the different arrangement of rivets connected to the classification, including different interval rivet connection program. The structure is a flanging connection.

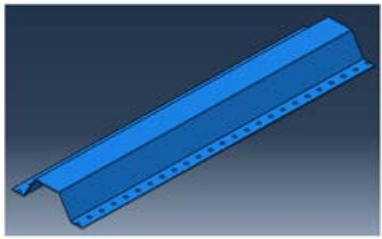

(a)

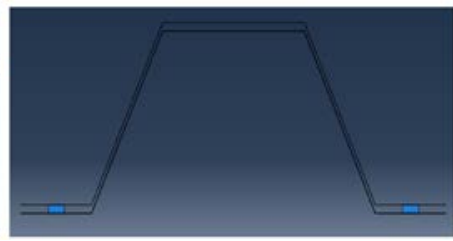

(b)

Fig.6(a)Rivet spacing diagram (b) model for the connection

Table 3 Simplified parameter list for rivet connection

\begin{tabular}{|c|c|c|c|c|c|}
\hline Name & $\begin{array}{c}\text { connection } \\
\text { model width }\end{array}$ & $\begin{array}{c}\text { Bevel } \\
\text { angle of } \\
\text { model }\end{array}$ & $\begin{array}{c}\text { Connection } \\
\text { model } \\
\text { height }\end{array}$ & $\begin{array}{c}\text { Connection } \\
\text { model } \\
\text { length }\end{array}$ & rivet space \\
\hline $\mathrm{a}$ & $86 \mathrm{~mm}$ & $60^{\circ}$ & $15.5 \mathrm{~mm}$ & $288 \mathrm{~mm}$ & $24.77 \mathrm{~mm}$ \\
\hline $\mathrm{b}$ & $86 \mathrm{~mm}$ & $60^{\circ}$ & $15.5 \mathrm{~mm}$ & $288 \mathrm{~mm}$ & $37.15 \mathrm{~mm}$ \\
\hline $\mathrm{c}$ & $86 \mathrm{~mm}$ & $60^{\circ}$ & $15.5 \mathrm{~mm}$ & $288 \mathrm{~mm}$ & $49.5 \mathrm{~mm}$ \\
\hline $\mathrm{d}$ & $86 \mathrm{~mm}$ & $60^{\circ}$ & $15.5 \mathrm{~mm}$ & $288 \mathrm{~mm}$ & $59.4 \mathrm{~mm}$ \\
\hline $\mathrm{e}$ & $86 \mathrm{~mm}$ & $60^{\circ}$ & $15.5 \mathrm{~mm}$ & $288 \mathrm{~mm}$ & $74.3 \mathrm{~mm}$ \\
\hline
\end{tabular}

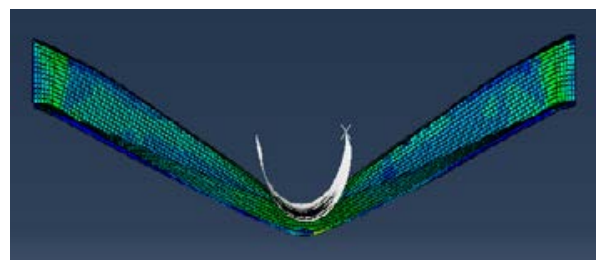

(a)

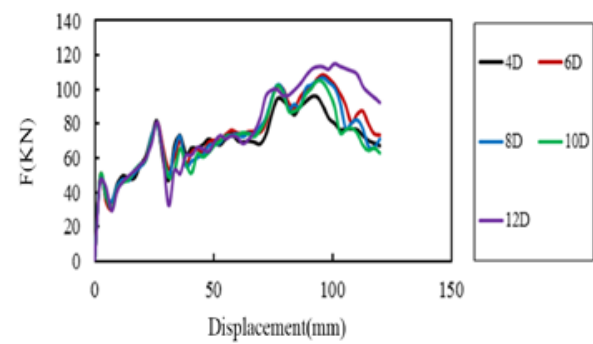

(b)

Fig.7 (a) Collapsing deformation diagram (b) Displacement diagram 
Table 4 Simplified model simulation results

\begin{tabular}{|c|c|c|c|c|c|c|}
\hline Name & $\begin{array}{c}\text { connection } \\
\text { model } \\
\text { width }\end{array}$ & $\begin{array}{c}\text { Bevel } \\
\text { angle } \\
\text { of } \\
\text { model }\end{array}$ & $\begin{array}{c}\text { Connection } \\
\text { model } \\
\text { height }\end{array}$ & $\begin{array}{c}\text { Connection } \\
\text { model length }\end{array}$ & rivet space & $\begin{array}{c}\text { Maximum } \\
\text { load }\end{array}$ \\
\hline $\mathrm{a}$ & $86 \mathrm{~mm}$ & $60^{\circ}$ & $15.5 \mathrm{~mm}$ & $288 \mathrm{~mm}$ & $24.77 \mathrm{~mm}$ & $99 \mathrm{KN}$ \\
\hline $\mathrm{b}$ & $86 \mathrm{~mm}$ & $60^{\circ}$ & $15.5 \mathrm{~mm}$ & $288 \mathrm{~mm}$ & $37.15 \mathrm{~mm}$ & $108 \mathrm{KN}$ \\
\hline $\mathrm{C}$ & $86 \mathrm{~mm}$ & $60^{\circ}$ & $15.5 \mathrm{~mm}$ & $288 \mathrm{~mm}$ & $49.5 \mathrm{~mm}$ & $108 \mathrm{KN}$ \\
\hline $\mathrm{d}$ & $86 \mathrm{~mm}$ & $60^{\circ}$ & $15.5 \mathrm{~mm}$ & $288 \mathrm{~mm}$ & $59.4 \mathrm{~mm}$ & $108 \mathrm{KN}$ \\
\hline $\mathrm{e}$ & $86 \mathrm{~mm}$ & $60^{\circ}$ & $15.5 \mathrm{~mm}$ & $288 \mathrm{~mm}$ & $74.3 \mathrm{~mm}$ & $112 \mathrm{KN}$ \\
\hline
\end{tabular}

From the final simulation results, in the case of no slippage deformation of the parts, different rivets interval does not significantly affect the bearing capacity of parts, parts bearing capacity is still mainly depends on the material properties of the parts themselves.

\subsection{Cap-shaped rivet connection three-point simulation}

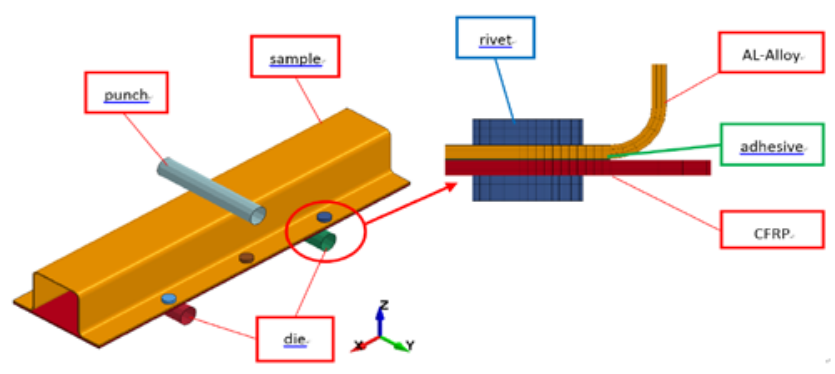

Fig.8 Three - point bending simulation model

In the simulation, the rivets, molds and punches are set into rigid bodies. The properties of the carbon fiber plate are set according to the uniaxial tensile results of the carbon fiber plate. The remaining detailed parameters are provided by the manufacturer or through the experiment.

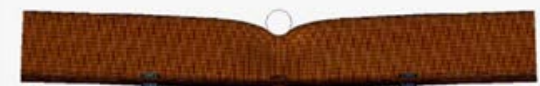

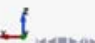

(a)

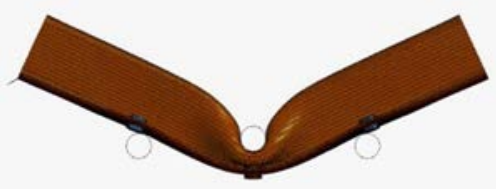

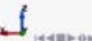

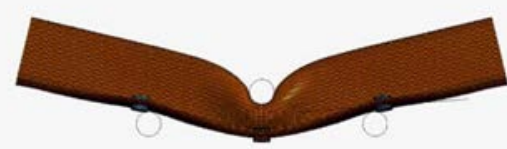

1

(b)

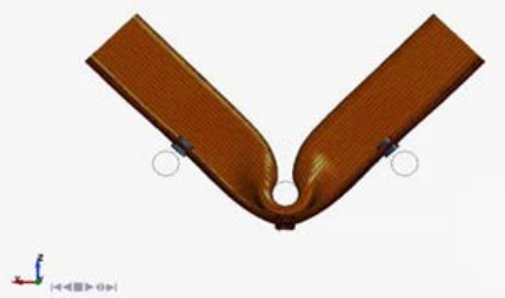

(d)

(c)

Fig.9 Three-point bending process 
It can be seen from Fig.9, from the front view, the aluminum alloy in the concave and carbon fiber plate bending process and the experiment basically consistent, in order to better contrast simulation and experimental carbon fiber plate damage form, we select The deformation process of carbon fiber plate under equivalent stress, as shown in Fig.10.

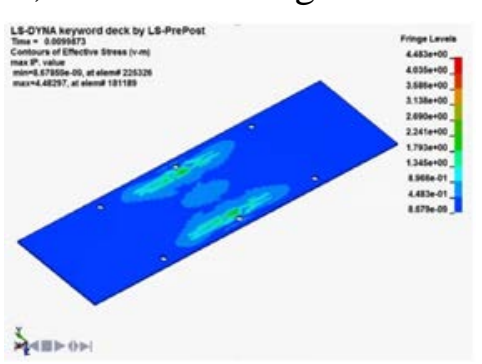

(a)

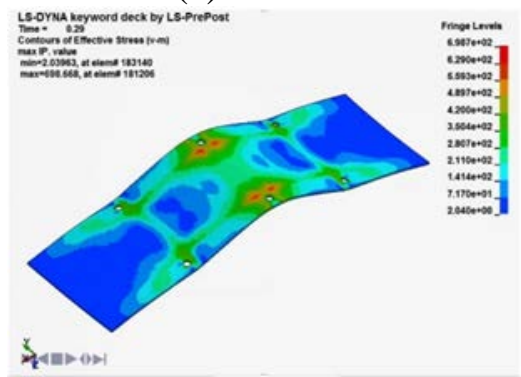

(b)

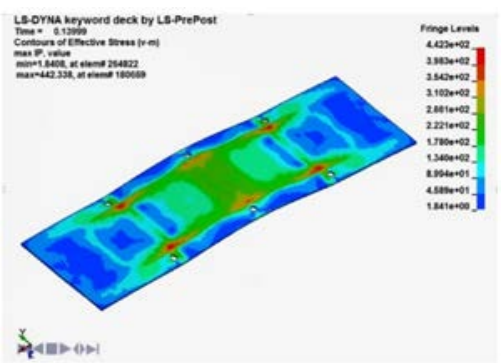

(b)

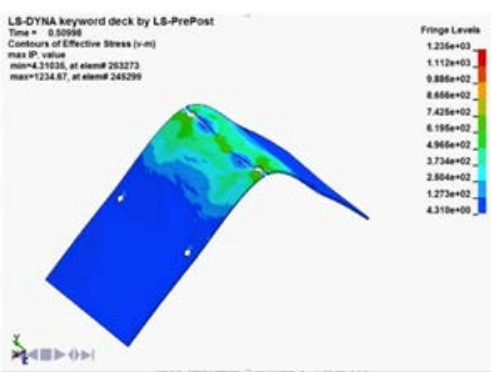

(d)

Fig.10 Carbon fiber deformation process

By comparing Fig. 9 and Fig. 10, it can be seen that the deformation of the carbon fiber plate is basically the same in the experiment and simulation. It can be seen from the simulation that the stress inside the rivet is relatively large. With the punching down, the rivet internal stress will be more and more, and finally also cracked in the middle of the rivet. However, because the specific parameters of carbon fiber board is not defined, it is impossible to simulate the process of carbon fiber filament fracture in simulation.

The test specimen is the aluminum alloy plate bent into a hat-shaped pieces, and carbon fiber board through the rubber riveting connected together, and then tested.

\subsection{Experimental validation}

In order to compare the effect of the number of rivets (or spacing) on the experimental performance of the three-point bending, we conducted four experiments, the size of the sample and the area of the glue, the number of rivets and the distance between the rivets as shown below:

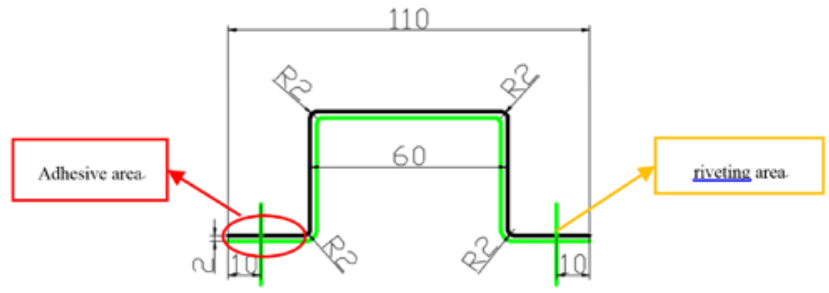

Fig.11 Section size 

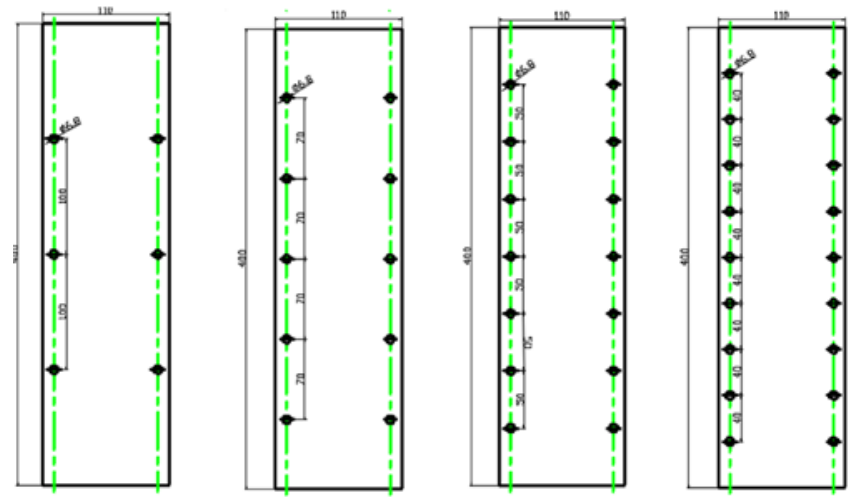

Fig.12 Rivets distribution

The actual diagram of the aluminum alloy plate and the sample glue riveting connection is shown below
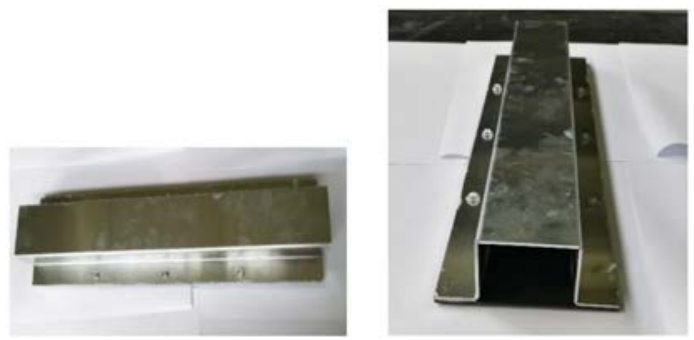

Fig.13 Test sample

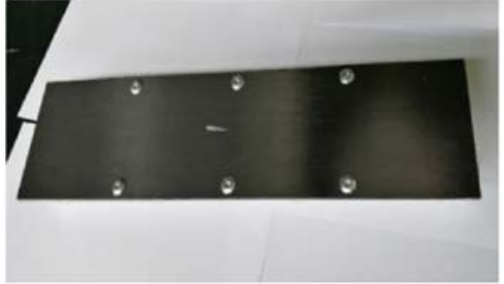

(a)

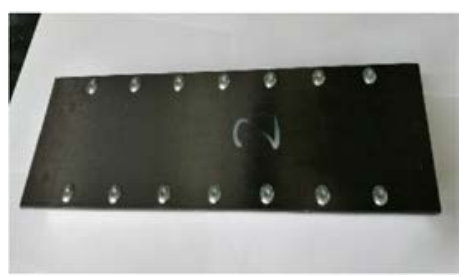

(c)

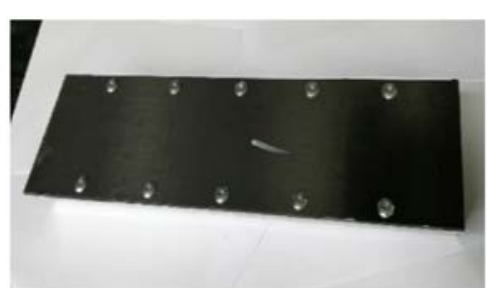

(b)

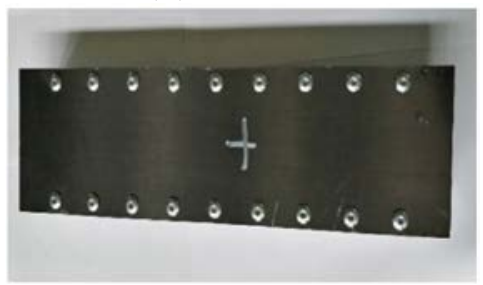

(d)

Fig.14 Different rivets number of test sample

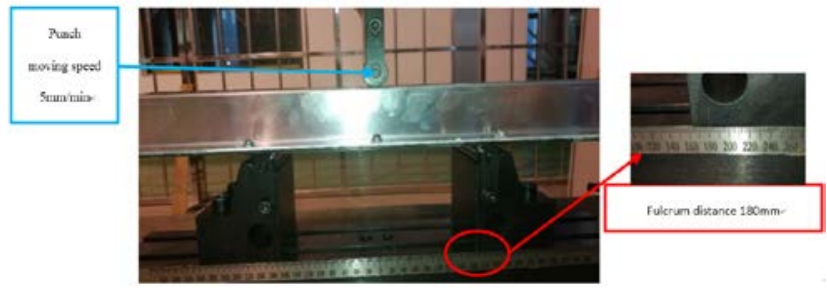

Fig.15 Test equipment 
In the whole three-point bending experiment, although the number of unilateral rivets were 3,5,7,9 four groups, but the sample of aluminum and carbon fiber plate deformation process basically the same. Taking the three rivets as an example, the shape change process and the bending process of the carbon fiber plate in the three-point bending experiment are shown in Figs. 13.

The shape change process of the specimen and the bending process of the carbon fiber plate in the three-point bending experiment are shown in Fig. 15:

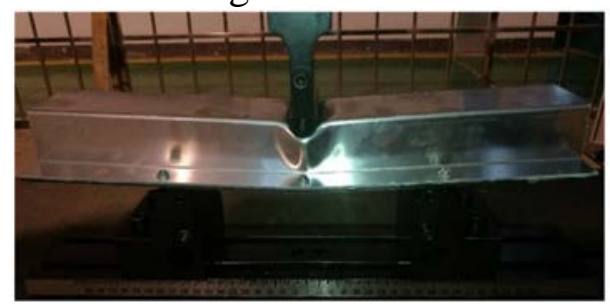

(a)

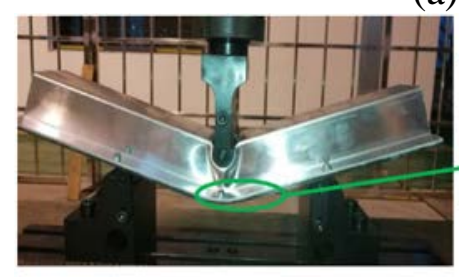

(b)

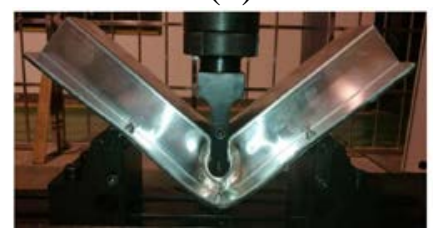

(d)

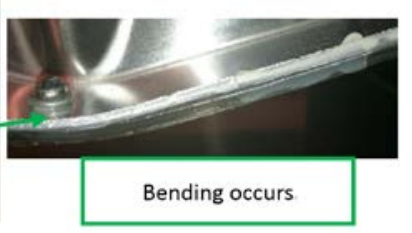

(c)

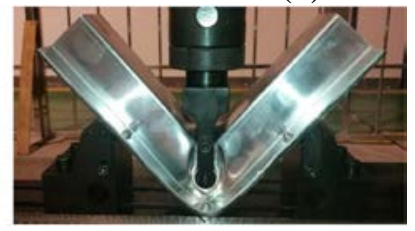

(e)

Fig.15 Deformation process

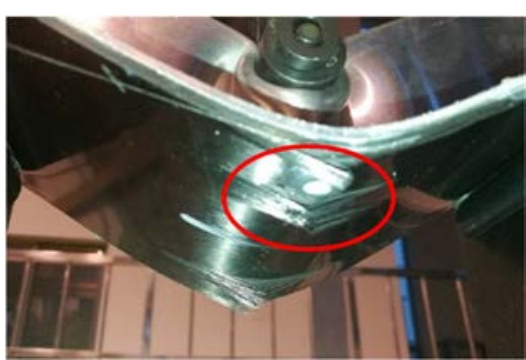

(a)

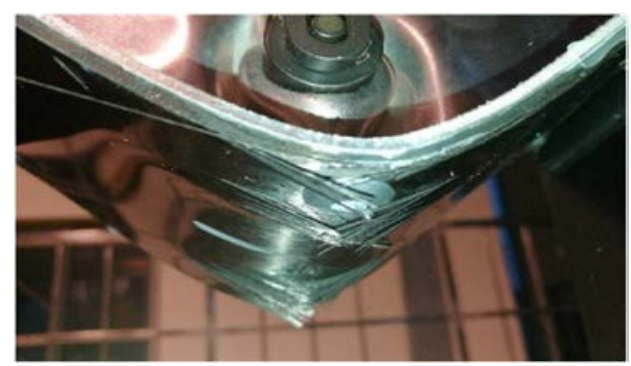

(b)

Fig.16 Carbon fiber damage diagram

It can be seen from Fig. 16 that the initial occurrence of the aluminum alloy material and the slight bending of the carbon fiber plate occur when the aluminum alloy is recessed to a certain extent. As the punch moves down, the bending of the carbon fiber plate is intensified, The degree of recession of the alloy is further deepened. In this process, the phenomenon of peeling with the carbon fiber plate occurs. When the carbon fiber is further bent, the carbon fiber plate breaks. The final test is completed and the displacement of the punch is $210 \mathrm{~mm}$.

In the whole process, the number of rivets has no effect on the deformation process of the aluminum alloy and the carbon fiber plate in the sample, but it affects the size of the opening when the adhesive is peeled off with the carbon fiber plate. The more the number of long rivets, split less obvious. 
It can be seen from Figure 15 that the beginning of the carbon fiber plate is only slightly bent; with the further deepening of the degree of bending can be seen in the middle of the middle of the rivet on both sides of the position, will gradually occur in the fracture of carbon fiber yarn; and carbon fiber yarn is gradually broken The final test is completed when the fracture of the carbon fiber plate is concentrated on both sides of the rivet.

In the whole three-point bending test, the displacement load curve is shown in Fig. 16:

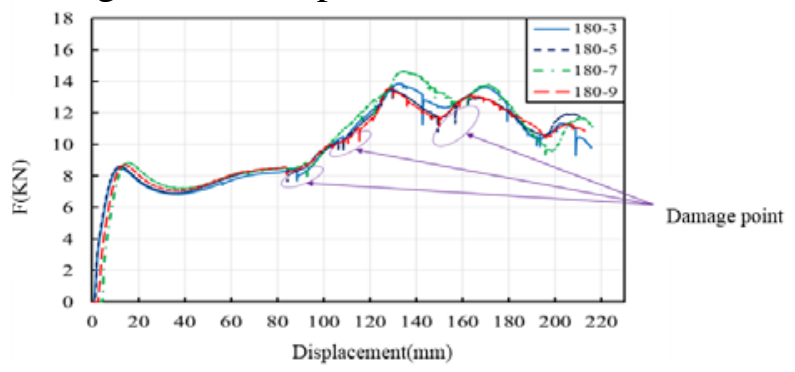

Fig.16 Displacement curve

From the three-point displacement-load curve, it can be seen that the number of uniaxial rivets has little effect on the results of the three-point bending test. For the unilateral rivet number of 3,5,7,9 four groups of experiments, The results of the curve are basically the same, but the maximum load is slightly different.

\section{Conclusions}

The simplified model of B - pillar reinforcement section is used to simulate the real collision situation design. For the different connection strength components to simulate, from the simulation situation can be seen corresponding to the body B-pillar of the beam, when the parts reach a certain connection strength, the three-point bearing load force does not occur. In the design of the component connection can also refer to the conclusions of the simulation.

By comparing the actual deformation process of different groups of samples, it can be found that the deformation of aluminum alloy with the deformation of carbon fiber plate deformation, deformation is controlled by carbon fiber board. And the peeling phenomenon of the adhesive layer and the carbon fiber plate occurs, and when the number of rivets is increased or the rivet pitch is reduced, the opening of the adhesive layer at the end of the experiment is less noticeable.

Through the three-point displacement-load curve can be seen, because the deformation is subject to carbon fiber, riveting spacing is mainly affected by the peeling of the adhesive layer, the deformation process for the little effect, the maximum load is different, but the difference is very little.

Too much of the welding connection, or too much riveting connection, does not increase the crashworthiness of the vehicle, but too many connected rivets will increase the weight of the vehicle, too many solder joints will be too Resulting in an increase in production costs. So the final connection interval is maintained at $50 \mathrm{~mm}-60 \mathrm{~mm}$, that is, the existing vehicle solder joint spacing standard is a reasonable interval of a reasonable interval.

\section{References}

[1] Li X, He L, Zhou H,. Influence of silicone oil modification on properties of ramie fiber reinforced polypropylene composites. Carbohyd Polym 2012; 87: 2000-2004.

[2] Zhou N, Yu B, Sun J,. Influence of chemical treatments on the interfacial properties of ramie fiber 
reinforced poly (lactic acid)(PLA) composites. J Biobased Mater Bio 2012; 6: 564-568.

[3]Gu Y, Tan X, Yang Z,. Hot compaction and mechanical properties of ramie fabric/epoxy composite fabricated using vacuum assisted resin infusion molding. Mater Design 2014; 56: 852-861.

[4]Oktem H, Erzurumlu T, Uzman I. Application of Taguchi optimization technique in determining plastic injection molding process parameters for a thin-shell part. Mater Design 2007; 28: 1271-1278.

[5] Zhou M, Li Y, He C,. Interfacial crystallization enhanced interfacial interaction of poly (butylene succinate)/ramie fiber biocomposites using dopa mine as a modifier. Compos. Sci. Technol., 2014; 91: $22-29$ 